\title{
The Use of Humourous Texts in Improving ESL Learners' Vocabulary Comprehension and Retention
}

\author{
Nursyafiqah Binti Zabidin ${ }^{1}$ \\ ${ }^{1}$ Faculty of Education, Universiti Teknologi MARA (UiTM), Selangor, Malaysia \\ Correspondence: Nursyafiqah Binti Zabidin, Faculty of Education, Universiti Teknologi MARA (UiTM), \\ Kampus 17, Shah Alam, Selangor, Malaysia. Tel: 60-176-150-790. E-mail: syafiqah.zabidin@gmail.com
}

Received: June 17, 2015 Accepted: August 10, 2015 Online Published: August 11, 2015

doi:10.5539/elt.v8n9p104 URL: http://dx.doi.org/10.5539/elt.v8n9p104

\begin{abstract}
Successful language acquisition requires extensive word knowledge. However, learners are reportedly unable to increase their word knowledge due to insufficient meaningful input in the language classrooms. This paper intended to present another tool to encourage learners' vocabulary development. It examined the effect(s) of using short narrative jokes on ESL learners' word comprehension and retention. The study involved an experiment in which two intact groups of tertiary students attended four reading sessions. In each reading session, before they began reading, the participants were given a vocabulary test (pre-test) to measure vocabulary recognition of the target words. The experimental group was then exposed to short humourous text while the control group was exposed to comparable non-humourous text. After each reading session, the participants were given immediate vocabulary test (post-test 1) to measure vocabulary comprehension. After a week, the participants were given delayed vocabulary test (post-test 2) to measure vocabulary retention. The participants' gain scores were assessed by comparing their post-test 1 to pre-test score. Lastly, the gain scores and scores in delayed vocabulary test of the two groups were compared using $t$ test. The findings of this study indicated that humour could relatively influence word comprehension and retention. One of its implications is for language teachers to include humour in vocabulary teaching and learning.
\end{abstract}

Keywords: humour, jokes, vocabulary comprehension, vocabulary retention, ESL, tertiary students

\section{Introduction}

Words are the essence of a language (Behlol \& Kaini, 2011). Without a sound knowledge of vocabulary, one would demonstrate poor reading performance as well as low interest in reading (Jalongo \& Sobolak, 2011). Low vocabulary level could also make it difficult for learners to perform in speaking, listening and writing, thus hindering their language acquisition (Ali, Mukundan, Baki, \& Ayub, 2012; Mokhtar et al., 2010). Adult students in Malaysia have been reported to possess poor vocabulary knowledge (Mokhtar et al., 2010) that might be due to insufficient meaningful input in the language classrooms (Nadarajan, 2009). It has also been found that conventional vocabulary activities, such as spelling and read aloud, may promote immediate vocabulary comprehension, but fail to encourage vocabulary retention (Nadarajan, 2009).

Therefore, a large number of studies could be found on more pedagogical strategies for vocabulary teaching. At the same time, studies have also established the positive role of humour in teaching, including in the language classrooms. Garner (2006) and Matthews (2011) reported that humour indeed encouraged memory retention among learners. Bell (2009), Ness (2009) and Schmitz (2002) asserted in their studies that humour can facilitate language teaching and learning, including vocabulary acquisition.

\subsection{Vocabulary Teaching}

Vocabulary is known as knowledge of words and word meanings (Butler, Urrutia, Buenger, Gonzalez, Hunt, \& Eisenhart, 2010). Generally, vocabulary knowledge is divided into two types. Receptive or passive vocabulary refers to interpreting and retrieving the meaning of a word that is heard or read while expressive or active vocabulary refers to producing the appropriate word one wants to express through speech or writing (Jalongo \& Sobolak, 2011). Together, they form one's Receptive and Productive Vocabulary (RPV). RPV processes refer to subconscious mental processes involved in recognition, recall, retrieval, comprehension and production of words (Mokhar et al., 2010). Vocabulary is crucial in successful language acquisition and academic performance. Poor 
vocabulary knowledge could lead to several obstacles in reading, writing and overall academic success (Ali et al., 2012) which was the case found among young adults in Malaysia (Mokhtar et al., 2010).

Therefore, numerous studies on vocabulary teaching and learning have attempted to introduce suitable means of integrating vocabulary in language learning. Conventional vocabulary instructional strategies, such as out-of-context "Word of the day" activities and the activities of reading long texts, have been reported to encourage immediate vocabulary comprehension (August, 2011), but frequently fail to ensure learners' interest and motivation (Merisuo-storm, 2006), active participation (Jalongo \& Sobolak, 2011) and vocabulary growth (Nadarajan, 2009). Other common strategies like reading aloud and repetition have been found to cause anxiety among students (Merisuo-storm, 2006). Language teachers are also encouraged to teach independent vocabulary learning strategies (VLS) in order to encourage learners' vocabulary development (Mokthar et al., 2010). Strategies, such as using dictionary, contextual clues and computer to find word meanings are found to be influential in vocabulary growth. Once exposed to these independent strategies, the leaners can then choose vocabulary learning strategies that suit their learning style. These strategies enable learners to become independent word learners whenever they are confronted with unfamiliar words.

The research-based instructional strategies also explored the comparison between implicit and explicit teachings of vocabulary. Nadarajan (2009) found that higher gain scores of vocabulary learning were obtained through implicit (in context) instruction, such as text reading, compared to explicit (direct) instruction, such as spelling bee. Even though both types of instructions encouraged vocabulary growth, implicit instruction reported higher gain scores. Mokhtar et al. (2010) and Nadarajan (2009) suggested that in order to increase word knowledge, wide reading and easy texts, including texts that are simply for enjoyment, should be introduced. Merisuo-Storm (2006) documented that humourous stories were one of the favourite reading texts among younger students. He also established that reading material strongly influences students' attitude towards reading.

\subsection{Humour in Teaching}

Humour can be described as the comic, absurd or incongruous quality that causes amusement (Matthews, 2011). Narrative joke, one example of humour, is a brief fictional dialogue that is concluded with the punch line (line that contradicts with expectation and general knowledge and causes reinterpretation of the whole text) (Tsakona, 2003). One of the theories in determining what one describes as humourous is Incongruity Theory. Incongruity Theory is the feeling of amusement which derives from the unexpected or surprise that contradicts with past experience, cognitive frameworks and expectations (Kozbelt \& Nishioka, 2010; Perks, 2012). Even though it is subjective in nature, humour value can be measured with the rating of an appropriate sample from any population (Kozbelt \& Nishioka, 2010). In his study to determine the effect of humour on memory, Carlson (2011) found that humourous stimuli predicted better recall compared to inspirational stimuli.

In the teaching context, Garner (2006) and Matthews (2011) reported that insertion of humour in classrooms leads to strong content retention and overall learning enjoyment. In language teaching and learning, Wagner and Urios-Aparisi (2011) found that using humour in classroom assists instruction and promotes immediacy, satisfaction, agreement and motivation. They also documented that humour could be a tool to encourage students' development in language acquisition as well as cultural knowledge. Bell (2009) stated that humour could encourage language play and assist the acquisition of target language through drama, memorization and imitation of humour samples the students came across with.

In addition, jokes and humourous anecdotes have been suggested as an aid in introducing new vocabulary. Ness (2009) asserted that jokes could introduce new vocabulary (including homophones and words with multiple meanings) as they entailed an understanding of word puns and word play, stress and emphasis on certain words as well as the ability to approach texts in appropriate word phrases and chunks. Jokes and humourous anecdotes, are also deemed to be pedagogically useful as they are short and provide learners with light reading compared to longer reading materials (Schmitz, 2002). It is through these texts that vocabulary could be highlighted in the language classrooms. There are also documented calls for more empirical studies on the use of humour in language classrooms (Schmitz, 2002; Wagner \& Urios-Aparisi, 2011).

\subsection{Research Questions and Hypotheses}

This study aimed to answer the following questions:

1) Is there any significant difference between gain scores of students exposed to humourous text and gain scores of students exposed to non-humourous text?

2) Is there any significant difference between retention scores of students exposed to humourous text and retention scores of students exposed to non-humourous text? 
These questions led to the following hypotheses:

1) There is no significant difference between gain scores of students exposed to humourous text and gain scores of students exposed to non-humourous text.

2) There is no significant difference between retention scores of students exposed to humourous text and retention scores of students exposed to non-humourous text.

\section{Method}

\subsection{Participants}

This study applied an experiment and the participants were semester one diploma students of Universiti Teknologi MARA, Melaka, Malaysia. Two intact classes of the same programme were included: one group (9 males and 16 females) was the experimental group while the other ( 8 males and 17 females) was the control group. The two classes were chosen as both consisted of students with English grades within a specified range (two grades above and below B) in a national examination, Sijil Pelajaran Malaysia (SPM).

\subsection{Materials}

The selection of jokes was done in a pilot study, prior to the experiment. It involved a group of 20 students who was randomly selected from target population and presented with a questionnaire containing a set of 10 narrative jokes taken from the humour section of Reader's Digest Asia. In the questionnaire, the participants were asked to read the jokes and rate the narrative jokes by deciding if the jokes were: 1) not funny at all, 2) slightly funny, 3) moderately funny, and 4) very funny, in order to select the humourous material to be used in the experiment. Based on the participants' rating, only jokes that received the mean score of more than 2.5 would be selected.

The students were also asked to circle the words that they did not know the meaning of. Deni, Zainal \& Mohamed (2007) indicated that target words for vocabulary assessments could be identified by participants from the target population. Besides that, they also had to underline which part of the joke that they found funny. This was to identify the punch line of the jokes which would later be edited in order to produce comparable non-humourous text. Replacing the punch line with non-humourous sentence was assumed to remove the humour value of the stimulus.

After the questionnaire in this pilot test was collected and analysed, eight jokes were found to receive more than 2.5 as their mean score (refer to Table 1). Out of the eight jokes, only four with more target words were selected to be applied in the experiment. The sentences that the participants found funny (punch line) in the selected jokes were then edited and replaced with non-humourous sentences in order to produce comparable non-humourous texts. Therefore, both humourous and non-humourous texts were comparable and contained identical words that were measured in identical format in the pre-test and post-tests.

Table 1. Mean score of the narrative joke rating

\begin{tabular}{lllllllllll}
\hline & Joke 1 & Joke 2 & Joke 3 & Joke 4 & Joke 5 & Joke 6 & Joke 7 & Joke 8 & Joke 9 & Joke 10 \\
\hline Mean Score & 2.05 & 2.50 & 2.80 & 3.20 & 2.60 & 2.65 & 3.15 & 2.75 & 2.90 & 2.55 \\
\hline
\end{tabular}

\subsection{Instruments}

Instruments in this study included a questionnaire used in the pilot study in order to find humourous texts for the actual experiment. Another instrument used was the vocabulary test (multiple-choice questions). The same vocabulary test was used as pre-test, post-test 1 and post-test 2 . The vocabulary test required students to match the definitions given to the correct word (reversal of standard practice) so that they would have to check each option of words against the definitions while answering the questions. The content validity of the test was determined by seeking the opinion of two lecturers with more than 10 years of English teaching experience.

The reliability of the test was addressed by administering a test-retest. Another group of 20 students was invited to participate in the test-retest of the vocabulary test with a gap of a week between the first and the second tests. The items and options were presented in randomized order in the second test to reduce the possibility of participants memorizing the items in the test. According to Creswell (2012), a test-retest presents an advantage of requiring only one form of the instrument. Based on Pearson Correlation Coefficient, the test and retest scores were found to correlate at a medium level ( $r=0.57$ to 0.58$)$.

\subsection{Procedures}


In the experiment, the two groups attended four reading sessions conducted by the researcher. In each session, one short text was studied. At the beginning of the session, the participants were given pre-test to observe vocabulary recognition of the target words. Humourous text was next presented to the experimental group while the control group received non-humourous text. They were then asked to answer the immediate vocabulary test (post-test 1) to measure vocabulary comprehension. The participants were given 30 minutes to read the text and answer the vocabulary test. After a week, the participants were given delayed vocabulary test (post-test 2) to assess vocabulary retention. In order to reduce the test practice effect, the delayed vocabulary test was given a week after the immediate vocabulary test was given and the items as well as the options were presented in randomized order. Similar procedure was repeated in all reading sessions.

\section{Results}

\subsection{Preliminary Analysis of Means of Scores in Pre-test and Post-test 1}

Preliminary analysis included the examination of participants' means of scores in pre-test and post-test 1 . Their scores were analysed separately according to sessions since the comprehension test was taken right after each reading session and the retention test was done a week after. Thus, the two groups' performance could be distinctly observed and analysed for each reading session. Analysis revealed that participants' scores increased from pre-test to post-test 1 , indicating vocabulary comprehension that occurred after exposure to the reading material.

Table 2. Mean and SD for participants' scores in pre-test and post-test 1

\begin{tabular}{lllllllll}
\hline & \multicolumn{2}{l}{ Session 1} & \multicolumn{2}{c}{ Session 2 } & \multicolumn{2}{c}{ Session 3 } & \multicolumn{2}{c}{ Session 4 } \\
\cline { 2 - 8 } Experiment. Mean & Pre-test & Post-test 1 & Pre-test & Post-test 1 & Pre-test & Post-test 1 & Pre-test & Post-test 1 \\
\cline { 2 - 9 } N & 2.88 & 3.24 & 3.40 & 3.84 & 3.48 & 4.80 & 2.24 & 3.40 \\
SD & 25 & 25 & 25 & 25 & 25 & 25 & 25 & 25 \\
Control Mean & 2.56 & 3.76 & 3.28 & 3.84 & 3.08 & 4.68 & 2.68 & 3.68 \\
N & 25 & 25 & 25 & 25 & 25 & 25 & 25 & 25 \\
SD & 1.12 & 0.52 & 0.74 & 0.37 & 1.26 & 0.56 & 1.07 & 0.56 \\
Total Mean & 2.72 & 3.50 & 3.34 & 3.84 & 3.28 & 4.74 & 2.46 & 3.54 \\
N & 50 & 50 & 50 & 50 & 50 & 50 & 50 & 50 \\
SD & 1.16 & 0.76 & 0.69 & 0.37 & 1.40 & 0.69 & 0.99 & 0.71 \\
\hline
\end{tabular}

\subsection{Further Analysis Using $t$ Test}

For further analysis, participants' scores in post-test 1 were compared to pre-test (gain scores) to examine vocabulary comprehension. Meanwhile, vocabulary retention is assessed by examining participants' scores in post-test 2 (retention scores). The significant level was set at 0.05 . Using SPSS, the following results were produced.

Hypothesis one: There is no sigificant difference between gain scores of students exposed to humourous text and gain scores of students exposed to non-humourous text.

$t$ test was used to compare the gain scores obtained by participants exposed to humourous texts $(n=25)$ to those exposed to non-humourous texts $(n=25)$. In Session 1, there was significant difference in gain scores $(\mathrm{p}=0.04)$, with experimental group $(M=0.36, S D=0.7)$ reporting mean of 0.8 lower than control group $(M=1.16, S D=$ 1.1). Meanwhile, results revealed that there was no significant difference in gain scores $(p=0.47)$ in Session 2 , with experimental group $(M=0.44, S D=0.58)$ reporting mean of 0.12 lower than control group $(M=0.56, S D=$ 0.58). In Session 3, there was no significant difference recorded $(\mathrm{p}=0.421)$, with experimental group $(M=1.32$, $S D=1.34)$ reporting mean of 0.28 lower than control group $(M=1.6, S D=1.08)$. Results also indicated no significant difference in Session $4(\mathrm{p}=0.446)$, with experimental group $(M=1.24, S D=1.05)$ reporting mean of 0.24 higher than control group $(M=1.0, S D=1.15)$. The $t$ test in Session 1 was statistically significant while the $t$ test in Session 2, 3, and 4 were non-significant as shown in Table 3. 
Table 3. $t$ Test comparing gain scores of participants in experimental and control groups

\begin{tabular}{lllll}
\hline Gain Scores & $t$ & $D f$ & $p$ & Mean Difference \\
\hline Session 1 & -3.056 & 40.56 & $0.04^{*}$ & -0.8 \\
Session 2 & -0.728 & 48 & 0.47 & -0.12 \\
Session 3 & -0.811 & 48 & 0.421 & -0.28 \\
Session 4 & 0.768 & 48 & 0.446 & 0.24 \\
\hline
\end{tabular}

$* \mathrm{p}<0.05$

Hypothesis two: There is no significant difference between retention scores of students exposed to humourous text and retention scores of students exposed to non-humourous text.

Retention scores obtained by participants exposed to humourous texts $(n=25)$ were compared to the scores of those exposed to non-humourous texts $(n=25)$ with independent samples $t$ test. In Session 1, results indicated no significant difference in retention scores $(\mathrm{p}=0.31)$, with experimental group $(M=3.12, S D=1.05)$ reporting mean of 0.28 lower than control group $(M=0.86, S D=0.17)$. There was no significant difference found in retention scores $(\mathrm{p}=0.764)$ in Session 2, with experimental group $(M=3.8, S D=0.5)$ reporting mean of 0.04 higher than control group $(M=3.76, S D=0.43)$. In Session 3, no significant difference was recorded $(\mathrm{p}=0.117)$, with experimental group $(M=4.76, S D=0.83)$ reporting mean of 0.36 higher than control group $(M=4.4, S D=$ 0.76). Results also revealed no significant difference in Session $4(\mathrm{p}=0.105)$, with experimental group $(M=$ $3.08, S D=1.15)$ reporting mean of 0.44 lower than control group $(M=3.52, S D=0.65)$. Table 4 shows that the $t$ test for all sessions were non-significant.

Table 4. $t$ Test comparing retention scores of participants in experimental and control groups

\begin{tabular}{lllll}
\hline Retention Scores & $t$ & $D f$ & $p$ & Mean Difference \\
\hline Session 1 & -1.027 & 48 & 0.310 & -0.28 \\
Session 2 & 0.302 & 48 & 0.764 & 0.04 \\
Session 3 & 1.595 & 48 & 0.117 & 0.36 \\
Session 4 & -1.661 & 37.99 & 0.105 & -0.44 \\
\hline
\end{tabular}

Based on the preliminary analysis, an increase of scores from pre-test to post-test 1 could be observed. Meanwhile, further analysis indicated that hypothesis one was accepted, except for Session 1 that showed significant difference. Hypothesis two was also accepted as there was no significant difference found in all four sessions.

\section{Discussion}

With regard to vocabulary comprehension, preliminary analysis revealed that participants in both groups showed ability to comprehend new vocabulary when they were given texts, regardless if the texts were humourous or not. This can be seen from both groups' mean of score that increased from pre-test to post-test 1. Further analysis indicated no significant difference in the two groups' gain scores. This infers that both humourous and non-humourous texts produced the same effect: assisting learners' word comprehension. In other words, the texts provided a context in which comprehension of new words can be achieved. This is in accordance with Mokhtar et al. (2010) and Nadarajan (2009) who asserted that reading easy text is an effective way to increase word comprehension.

The results also indicated that participants in control group obtained slightly higher mean of gain scores compared to those in experimental group. One explanation for this finding is that some participants in the experimental groups have already recognised the words included in the texts prior to the experiment. Thus, they managed to match the correct word to the definitions in pre-test and post-test 1 correctly and more gain scores of 0 were being recorded for the experimental group. Referring to the preliminary analysis of means of pre-test and post-test 1 scores, participants from experimental groups were recorded to receive higher pre-test scores compared to those in control group, indicating that some of them have already recognised the words prior to the experiment. However, as mentioned above, an increase of mean of scores from pre-test to post-test 1 showed a 
gain in word knowledge of most participants from both groups.

In terms of vocabulary retention, no significant difference was found. However, participants in experimental group obtained marginally higher mean of retention scores as compared to those in control group in two of the sessions. This implies that humourous texts could facilitate and encourage students' vocabulary retention and supports the claims made by Bell (2009), Ness (2009) and Schmitz (2002) that jokes can provide a useful platform to improve vocabulary knowledge. This also solidifies findings reported by Carlson (2011), Garner (2006) and Matthews (2011) that humour encourages stronger memory retention. A plausible explanation for this result is connected to the Incongruity Theory of humour. When one is confronted with humour, he or she has to solve the incongruity involved in order to understand humour. Resolving incongruity inevitably introduces a cognitive challenge to the readers, thus, triggers interest, motivation and attention as well as influences memory performance (Hayati, Shooshtari, \& Shakeri, 2011). Another probable explanation is reading materials affect attitude towards reading (Merisuo-storm, 2006) and readers' emotion while reading. Reading humourous materials engages emotion that makes remembering materials read more accurate and long lasting (Hayati, Shooshtari, \& Shakeri, 2011).

This specific study was not without limitations. Firstly, it included only four reading sessions. Besides that, the target words were not selected based on progressing levels of difficulty. Therefore, the limited number of sessions and selection of target words might not be sufficient to observe growth of vocabulary knowledge over time. This study also did not measure the participants' topic of interest in selecting the jokes as only the humour value of the texts (jokes) was measured. This might subsequently affect their word comprehension and recall.

\section{Conclusion}

This study was based on the belief that humourous texts have an effect on learners' vocabulary comprehension and retention. Its major aim was to assess if comprehension and retention of new words were affected by the use of jokes as reading material as compared to non-humourous texts. To achieve said aim, participants were required to attend four reading sessions and take vocabulary tests.

The preliminary analysis of gain scores revealed an increase in mean of participants' scores in both groups. This indicated that comprehension of new words can be aided by texts, including humourous material. In terms of vocabulary retention, experimental group did report higher mean of scores than control group in two of the sessions. The findings suggested a more relative influential role of humour, namely, jokes, on vocabulary retention. The results revealed that humour encouraged better retention ability as compared to non-humourous material. The implication of this study is for language teachers to include humour, along with other materials, in vocabulary teaching and learning. In addition, material developers and curriculum designers might also consider including humourous elements in their work.

\section{References}

Ali, Z., Mukundan, J., Baki, R., \& Ayub, A. F. (2012). Second language learners' attitudes towards the methods of learning vocabulary. English Language Teaching, 5(4), 24-36. http://dx.doi.org/10.5539/elt.v5n4p24

August, G. (2011). Spelling facilitates good ESL reading comprehension. Journal of Developmental Education, 35(1), 14-24.

Behlol, M., \& Kaini, M. M. (2011). Comparative Effectiveness of Contextual and Structural Method of Teaching Vocabulary. English Language Teaching, 4(1), 90-97. http://dx.doi.org/10.5539/elt.v4n1p90

Bell, N. D. (2009). Learning about and through humor in the second language classroom. Language Teaching Research, 13(241), 241-258. http://dx.doi.org/10.1177/1362168809104697

Butler, S., Urrutia, K., Buenger, A., Gonzalez, N., Hunt, M., \& Eisenhart, C. (2010). A Research Synthesis: A Review of the Current Research on Vocabulary Instruction. National reading Technical Assistance Center, RMC Research Corporation.

Carlson, K. A. (2011). The Impact of Humour on Memory: Is the Humour Effect about Memory? Humor, 24(1), 21-41. http://dx.doi.org/10.1515/humr.2011.002

Creswell, J. H. (2012). Educational Research: Planning, Conducting, and Evaluating Quantitative and Qualitative Research. Boston: Pearson Education, Inc.

Deni, A. R., Zainal, Z. I., \& Mohamed, M. (2007). Vocabulary Learning through Vocabulary Scrapbook. The Second Biennial International Conference on Teaching and Learning of English in Asia: Exploring New Frontiers (TELiA2), (pp. 1-11). Faculty of Communication and Modern Languages, Universiti Utara Malaysia, Sintok. . 
Garner, R. L. (2006). Humor in pedagogy: How ha-ha can lead to aha! College Reading, 54(1), 177-180. http://dx.doi.org/10.3200/ctch.54.1.177-180

Hayati, A. M., Shooshtari, Z. G., \& Shakeri, N. (2011). Using Humorous Texts in Improving Reading Comprehension of EFL Learners. Theory nd Practice in Language Practice, 1(6), 652-661. http://dx.doi.org/10.4304/tpls.1.6.652-661

Jalongo, M. R., \& Sobolak, M. J. (2011). Supporting young children's vocabulary growth: the challenges, the benefits and evidence-based strategies. Early Childhood Education Journal, 28, 421-429. http://dx.doi.org/10.1007/s10643-010-0433-x

Kozbelt, A., \& Nishioka, K. (2010). Humor comprehension, humor production, and insight: An exploratory study. Humor, 23(3), 375-401. http://dx.doi.org/10.1515/humr.2010.017

Matthews, M. L. (2011). A funny thing happened on the way to the hippocampus: The effects of humor on students achievement and memory retention (Doctoral Dissertation). Available from ProQuest Dissertation \& Theses.

Merisuo-storm, T. (2006). Girls and boys like to read and write different texts. Scandinavian Journal of Educational Research, 50(2), 111-125. http://dx.doi.org/10.1080/00313830600576039

Mokhtar, A. A., Rawian, R. M., Yahaya, M. F., Abdullah, A., Mansor, M., Osman, M. I., ... Abdul, R. M. (2010). Vocabulary knowledge of adult ESL learners. English Language Teaching, 3(1), 71-80. http://dx.doi.org/10.5539/elt.v3n1p71

Nadarajan, S. (2009). The effect of instruction and context on L2 learners' vocabulary development. Electronic Journal of Foreign Language Teaching, 2009(2), 177-189.

Ness, M. (2009). Laughing through rereadings: Using joke books to build fluency. The Reading Teacher, 62(8), 691-694. http://dx.doi.org/10.1598/RT.62.8.7

Perks, L. G. (2012). The Ancient Roots of Humor Theory. Humor, 25(2), 119-132. http://dx.doi.org/10.1515/humor-2012-0007

Schmitz, J. R. (2002). Humor as a pedagogical tool in foreign language and translation courses. Humor, 15(1), 89-113. http://dx.doi.org/10.1515/humr.2002.007

Tsakona, V. (2003). Jab lines in Narrative Jokes. Humor, 16(3), 315-329. http://dx.doi.org/10.1515/humr.2003.017

Wagner, M., \& Urios-Aparisi, E. (2011). The Use of Humour in Foreign Language Classroom: Funny and Effective? Humor, 24(4), 399-434. http://dx.doi.org/10.1515/humr.2011.024

\section{Appendix A}

\section{Humourous Text (Narrative Joke) Used in Session 4}

A mother went out and left a father to look after their 3-year-old daughter. The father was rarely left to watch over their daughter on his own. Apparently, the girl was playing with her favourite toy, a tea set. While the father was in the living room, engrossed in the evening news on the television, the girl brought him cups of 'tea', which were just water.

After several cups and lots of praises, the mother came home. The father made her wait in the living room to watch their daughter bring him a cup of tea. "It was just the most adorable thing!" the father exclaimed.

Sure enough, the girl came down the hall with a cup of tea for her father. The mother watched him drink it up.

Then, she said (with a mother's typical wisdom), "Did it ever occur to you that the only place she can reach to get water is the toilet bowl?"

Adapted from Reader's Digest Asia, by Corrie Liversage, May, 2011, page 57.

\section{Appendix B}

\section{Non-humourous Text Used in Session 4}

A mother went out and left a father to look after their 3-year-old daughter. The father was rarely left to watch over their daughter on his own. Apparently, the girl was playing with her favourite toy, a tea set. While the father was in the living room, engrossed in the evening news on the television, the girl brought him cups of 'tea', which 
were just water.

After several cups and lots of praises, the mother came home. The father made her wait in the living room to watch their daughter bring him a cup of tea. "It was just the most adorable thing!" the father exclaimed.

Sure enough, the girl came down the hall with a cup of tea for her father. The mother watched him drink it up.

Then, she said, "That sure was adorable. She really loves playing with her tea set and making some tea for people."

Adapted from Reader's Digest Asia, by Corrie Liversage, May, 2011, page 57.

\section{Appendix C}

\section{Vocabulary Test Used in Session 4}

Instruction: Circle the correct words that match the definitions given.

Example:

Definition: small
A. deep
B. quiet
C. tiny
D. tall

1. Definition: occupied all the time or attention in 3. Definition: said loudly; cried out something
A. praised
A. explained
B. engrossed
B. exclaimed
C. watched
C. murmured
D. exclaimed
D. muttered

2. Definition: not often; seldom

4. Definition: very delightful; loveable
A. apparently
B. typical
C. politely
D. rarely

A. typical

B. praises

C. adorable

D. wisdom

\section{Copyrights}

Copyright for this article is retained by the author(s), with first publication rights granted to the journal.

This is an open-access article distributed under the terms and conditions of the Creative Commons Attribution license (http://creativecommons.org/licenses/by/3.0/). 